\title{
Os Núcleos de Desenvolvimento de Recursos Humanos para a Saúde
}

\author{
Anete Pereira Simöes* * Médica-Sanitarista \\ Instituto de Saúde do Estado da \\ Bahus
}

\section{Emergência da Organização de Núcleos de Desenvolvimento de Recursos Humanos}

Para compreender a emergência da Organização de Núcleos de Desenvolvimento de Recursos Humanos nas Secretarias Estaduais de Saúde é necessário situá-la no contexto das políticas de saúde, e a estas, na conjuntura da Sociedade Brasileira em um momento determinado.

No Brasil, durante muito tempo, a formação de recursos humanos para o Setor Saúde, esteve a cargo das Universidades - no caso das profissōes de nivel superior - enquanto que aquela relacionada ao pessoal de nível médio e elementar esteve, predominante, a cargo das Instituiçōes responsáveis pela prestação de serviços, a partir de suas necessidades específicas, e através de iniciativas isoladas.

No caso específico da formação de pessoal, a área de saúde pública, mesmo a de nivel superior, sempre esteve sob a responsabilidade do Setor de prestação de serviços através do Ministério da Saúde e da Fundação Serviços de Saúde Pública.

A partir de 1964, se dá a incorporação do discurso e da prática do planejamento que vai servir como instrumento técnico-burocrático, no sentido de alcançar a racionalidade técnico administrativa nos aparelhos do Estado, tanto nas formulações da política econômica, quanto mais tarde nas políticas sociais.

Como no período de 64/74, a estratégia de desenvolvimento nacional, privilegiou o crescimento econômico e o controle político, o estilo de planejamento presente nos planos estatais (PAEG, PLAN Decenal, IPND) subordinava as politicas sociais (entre elas a de saúde) às políticas econômicas.

Mesmo assim, no âmbito da saúde, já no período 65/67, tanto no MS, quanto na previdência social ocorrem reorganizações internas, com formação de grupos de trabalho, assessorias etc. e o tema de "Formação de Recursos Humanos" já se evidencia com a preocupação de formar pessoal capacitado a exercer as funções de planejamento e adminstração e também proposições no sentido de equilibrar o qualitativo de pessoal de nível superior com o reduzido quadro de pessoal de nível técnico e auxiliar. ${ }^{5}$

A IV Conferência Nacional de Saúde realizada em 1967, ilustra estas preocupaçōes, apresentando como tema título "Recursos Humanos para a Saúde" - e dela emanam proposições à área, que todavia só vão encontrar condiçōes favoráveis à sua implantação após 1974.

Ainda neste período ocorre a unificação dos IAP's no Instituto Nacional de Previdência Social (1967) centralizando os

Cadernos de Saúde Pública, R.J., 2 (4): 553-560, out/dez, 1986 
recursos financeiros e o poder de decisão na área de saúde, fortalecendo ainda mais a previdência e, relativamente, fragilizando o Ministério da Saúde que tem sua participação no orçamento da União em níveis cada vez menores. A expansão da Previdência Social culmina com a criação do Ministério da Previdência e Assistência Social - MPAS em 1974, estando já nesse momento bem assentados os rumos que o setor salde veio assumindo, ou seja, capitalização acelerada, expansão do setor empresarial privado com privilégio da assistência médico-hospitalar e uso intenso de tecnologia. Ao nível da assistência prestada isso repercutia em altos custos, baixa eficácia, multiplicidade de modalidades assistenciais com exclusão de grandes grupos populacionais do acesso ao consumo de serviços.

A partir de 1974, findo o perfodo de expansão econômica e frente à crise política do Estado, é iniciada a gradual abertura política, e ganham força os questionamentos à política social ate então vigente, o que repercute na elaboração do II Plano Nacional de Desenvolvimento, que mesmo mantendo o privilégio da política econômica, já anuncia que a política social deve ter seus objetivos próprios, e nele já aparecem capítulos como: "Estratégia de Desenvolvimento Social" ou "emprego e recursos humanos".

Para Teixeira 5 , "evidencia-se nessa propostas a direção que se pretendia dar à questão social: o Estado encarregava-se de promover a dinamização dos setores sociais, segundo um padrão de racionalidade que não comporta a participação política da sociedade civil organizada, senão que baseia-se na visão economicista-tecnocrática da problemática social" e através do conteúdo retórico "o Estado busca legitimar-se frente às classes e às fraçōes das classes e sobre as quais recaíram os efeitos perversos do modelo: os baixos salários e a marginalização da estrutura produtiva".

Em 1976, com bases nas diretrizes do II PND e usando a abordagem da Teoria Geral dos Sistemas, surgiu a Lei 6.229, que criou o Sistema Nacional de Saúde, definindo as competências da União quanto ao Setor Saúde, através dos seus Ministérios, Estados e Munićpios.

Essa lei institucionaliza a dicotomia da assistência à saúde, quando atribui ao Ministério da Previdência da Previdência e Assistência Social, os cuidados curativos reabilitadores - individuais e ao Ministério da Saúde e às Secretarias de Saúde as ações preventivas - coletivas.

Essa e outras iniciativas (criação do MPAS, formulação do Plano de Pronta Ação - PPA, criação do Fundo de Assistência Social - FAS) são tentativas de enfrentar a crise estabelecida no Setor Saúde, a partir de uma compreensão desta, como decorrente da irracionalidade administrativa e portanto reforçam a utilização do planejamento como instrumento de reorganização do setor.

É neste contexto que se dá a emergência dos Programas de Extensão de Cobertura (PEC's), no Ministério da Saúde, vi- 
sando estender o acesso a serviço de saúde a grupos populacionais até então excluídos, especialmente as populações de baixa renda das zonas rurais. Os PEC's assumem os princípios da medicina comunitária, tais como: "privilégio da atenção primária, ênfase na forma e utilização de pessoal de nivel médio e elementar, as equipes multiprofissionais, a integração ensino-serviço, a utilização de tecnologia apropriada e a participação comunitária"3.

Esta proposta configura a possibilidade de expandir um modelo médico de baixo custo, complementar ao modelo médico-hospitalar hegemônico, e que tem o potencial de dar alguma resposta às demandas das populações marginalizadas.

Assim é que, em 1979, surge o Programa de Interiorização ds Ações de Saúde e Saneamento do Nordeste (PIASS) que em 1979 e estendido para todo o território nacional.

A implementação dos Programas de Extensão de Cobertura e os desdobramentos que ocorreram no interior das Secretarias Estaduais de Saúde (SES), tiveram papel determinante no início da organização dos Núcleos de Recursos Humanos, isto porque apesar de se tratar de uma proposta subalterna, dentro da organização da assistência à saúde, criaram espaços para a incorporação de práticas até então inovadoras na condução das ações das SES. Uma destas é o planejamento de recursos humanos, com vistas a atender às necessidades (novas) de pessoal, para a rede ampliada de serviços de saúde, com as características requeridas pela concepção da Medicina Simplificada.

Embora a formação de pessoal para a saúde a ser absorvida pelo mercado de trabalho que obedecia ao modelo de assistência hegemônica, houvesse continuado a ser desenvolvido pelas instituições educacionais e obedecendo ao modelo da medicina cientifica, as instituições de saúde pública (Ministério da Saúde - Secretarias Estaduais) passaram a se instrumentalizar para responder - com racionalidade - ao novo perfil de $\mathrm{RH}$, requerido.

O Ministério da Saúde, em acordo com o Ministério da Educação e com a Organização Pan-Americana da Saúde, propõe em 1975, o Programa de Preparação Estratégica de Pessoal de Saúde (PPREPS), em atendimento à indicação do Grupo Interministerial que havia sido criado, em 1974, para estudar a questão de $\mathrm{RH}$ em saúde e propor soluções a serem incorporadas ao II PND.

O PPREPS apresentava como propósito: "adequar progressivamente a formação de $\mathrm{RH}$ para a saúde com os requerimentos de um sistema de saúde com cobertura máxima possível e integral, regionalizada e de assistência progressiva de acordo com as necessidades das populações respectivas e as possibilidades das diversas realidades que o país apresenta."

Os projetos que compuseram o PPREPS destinaram-se a cobrir três áreas de atuação, sob a responsabilidade do Ministério da Saúde: planejamento de recursos humanos, preparação direta de pessoal para a saúde e apoio ao desenvolvimento do programa nacional de preparação e distribuição estratégica de pessoal de saúde. 
Entre os seus grandes objetivos, definia: "apoiar o estabelecimento de Sistema de Desenvolvimento de Recursos Humanos em cada Estado da federação, integrados aos sistemas de planejamento setorial respectivo", sendo a consecução deste objetivo o que poderia assegurar a continuidade de desenvolvimento de recursos humanos pelas Secretarias Estaduais.

Assim, as necessidades geradas pelo PEC's, que implicavam num redirecionamento da preparação de pessoal de saúde, passou a ser atendido pelas SES, que procuraram se adap$\operatorname{tar}$ técnica e administrativamente a esse modelo. No caso específico dos recursos humanos, esse processo deu origem ao fortalecimento dos núcleos de treinamento, muitos dos quais, depois, se trasformaram em núcleos de desenvolvimento de recursos humanos.

\section{A PROPOSTA DOS NÚCLEOS DE DESENVOLVIMENTO DE RECURSOS HUMANOS}

Nos anais da VII Conferência Nacional de Saúde, realizada em 1980, e que teve como tema título "Extensão das Ações de Saúde dos Serviços Básicos", o Ministério da Saúde define no documento "Proposição de diretrizes" que sua "ação estará voltada, fundamentalmente, para a implantação e desenvolvimento de serviços básicos de salide, com cobertura universal, e sob responsabilidade direta do setor público, sem prejuízo de um setor independente", e considera que "fator essencial e condição básicas principal para a realização das atividades de saúde, os recursos humanos serão objeto de atenção prioritária e integrada."

São considerados recursos humanos para a saúde o pessoal de todos os niveis, das instituições que atuam no setor, e entende-se por desenvolvimento de recursos humanos para a saúde "o processo dinâmico, integrado à política nacional de saúde, que visa ao aprimoramento técnico e ao crescimento pessoal e à evolução funcional dos trabalhadores do setor".

Dentro desta perspectiva, o Ministério da Saude, através da Sua Secretaria de Recursos Humanos apóia a formalização de orgãos de RH nas Secretarias, e em documento que divulga em 1982 ${ }^{1}$, destaca para eles as seguintes funçōes: 1) planejamento; 2) administração de pessoal; 3) Capacitação de Pessoal; 4) informação e documentação e 5) estudos e pesquisas.

É evidente que não seria indispensável a incorporação de todas estas funções a um só tempo e a intenção $\varepsilon$ que isto ocorre na medida das necessidades e do crescimento da instituição de saúde.

O planejamento de $\mathrm{RH}$ para a saúde corresponderia ao processo de formulação das propostas do conjunto de ações para a área, e seria orientado pela política de saúde. Através do planejamento é que deveria ser mobilizada a coordenação entre as diversas funções do órgão e, permitiria tamberm a avaliação e a reformulação. 
Quanto à função de adminstração de pessoal deveria envolver "um conjunto de procedimentos concebidos para administrar adequadamente os trabalhos das instituições visando a compatibilizar suas ações com os meios de trabalho existentes, para que desenvolvam sua atividades, produtivamente, na direção dos objetivos organizacionais, enquanto busca criar condições para que os objetivos individuais sejam realizados dentro da organização". Levando em consideração a abrangência dessa função, considera-se que ela não poderia estar afeta a um órgão, mas que se difundia por todos os níveis da instituição como componente do exercício da gerência dos serviços. A existência de um departamento de administração de pessoal se justificaria com a finalidade de centralizar certas atividades burocráticas e compatibilizar a política de pessoal da instituição. Os procedimentos atinentes a esta função seriam: elaboração de planos de cargos e salários; definições de plano de avaliação de desempenho; controle de cadastro e lotaçōes; coordenação das ações de recrutamento e seleção.

A capacitação de recursos humanos na área de saúde, especialmente no setor público, já vinha sendo historicamente assumida pelas instituições prestadoras de seviços, dada a situação diagnosticada de inadequação do processo formal de preparação de pessoal com referência a mercado de trabalho. Por isso essa função apareceu sempre como preponderante para o órgão de recursos humanos, sendo às vezes a única desenvolvida, dado as necessidades imediatas do serviço.

À função de capacitação caberia "preparar o trabalhador para a ocupação ou para a melhoria do seu desempenho no trabalho de produzir serviços de saúde adequados em quantidade e qualidade à realidade sanitária e cultural onde se inserem estes serviços." Embora a proposta explicitasse que a prioridade, então, deveria ser a formação de pessoal para operação da rede de cuidados primários, considerava que a função capacitação, em sua abrangência, deveria preparar recursos humanos para: o planejamento da ações de saúde e saneamento; a administração da rede de serviços, incluindo gerência e supervisão; a execução das ações de saúde e saneamento com tecnologia apropriada.

A informação e Documentação Científica, embora não sendo considerada uma função específica do desenvolvimento de recursos humanos, esteve incluída na proposta pela sua indispensabilidade no processo da capacitação, educação continuada e supervisão da rede de serviço de saúde, pela sua capacidade de seleção e divulgação do material bibliográfico e no intercâmbio de informações.

A incorporação da função - Estudos e Pesquisas - visava a produção do conhecimento na área, constituindo-se em instrumentos para a reflexão sobre o desenvolvimento de recursos humanos nas Secretarias Estaduais de Saúde, realimentando a proposta das ações e permitindo identificar a evolução qualitativa das experiências.

A implementação da proposta de formalização de núcleos de recursos Humanos, nas Secretarias de Saúde, teve desenvolvimento diferenciado nos diversos estados da federação, 
mas é evidente que a sua orientação e a concretização das suas práticas guardam relação com o objetivo de construir um modelo "alternativo" de atenção médico-sanitária, sob responsabilidade direita do Estado (os PEC's), o que implicava no redirecionamento da preparação de pessoal (nos seus aspectos quantitativo e qualitativo) e na reorganização técnico-administrativa das estruturas estaduais de saúde.

\section{PERSPECTIVAS ATUAIS}

A agudização da crise econômica que se evidencia a partir de 1981 tem sua correspondência no setor saúde.

Ocorrem nesta época a explicitação da falência financeira da Previdência Social, a avaliação do baixo nível de saúde da população brasileira e a constatação de incompetência da rede de serviços básicos de saúde em termos de resolutividade.

Algumas propostas de reformulação emergem neste período, entre elas o PREV-SAÚDE, que não chega a ser implementado, e a criação do CONASP - Conselho Consultivo da Administração de Saúde Previdenciária que definiu diretrizes racionalizadoras para a assistência ambulatorial e hospitalar a nível da Previdência Social, com a preocupação prioritária de reduzir custos.

No contexto da crise econômica há mudanças na situação política, nas eleições de 82, elegem-se vários governadores de oposição e a campanha das diretas culmina na eleição do Presidente Tancredo Neves (1984). A Nova República admite a crise no setor saúde, convive os questionamentos da sociedade civil quanto à política de saúde e dispõe de diferentes propostas alternativas para a solução, presentes nas formulações das diversas correntes políticas da Aliança Democrática e das organizações da sociedade ${ }^{4}$.

O diagnóstico da crise de organização sanitária brasileira é consensual quanto aos seguintes pontos: desigualdade no acesso aos serviços de saúde; in - Jequação dos serviços à estrutura das necessidades; baixá produtividade dos recursos existentes; crescimento elevado e descontrolado dos custos; qualidade insatisfatória dos serviços; inadequada estrutura de financiamento setorial; ausência de integralidade das ações de saúde; extrema diversidade das formas de produção e remuneração dos serviços; multiplicidade e descoordenação ds instituiçöes do setor; excessiva centralização do processo decisరrio; ineficácia social do sistema ${ }^{2}$.

Quanto ao nível das condições de saúde da população constata-se uma tendência à expansão de certas doenças para as quais já se dispõe de tecnologia resolutiva, além do baixo nível de saúde, diferenciado nas diversas categorias sociais e regiões do país.

Embora não se possa admitir que houve mudanças substanciais no setor saúde, na Nova República os avanços mais significativos vêm se dando através da estratégia das Ações Integradas de Saúde (AIS) e se explicitam na expansão da adesão dos Estados e Munićpios; acumulação de forças pelos grupos políticos favoráveis às AIS; elaboração de uma programação integrada (1986); o aperfeiçoamento do controle dos gastos 
públicos; o controle das fraudes; o incremento da produçãō nacional de imunobiologicos; 0 incentivo à pesquisa cientifica e tecnológica; etc.

Outro marco do setor, dentro da Nova Repáblica, foi a realização da VIII Conferência Nacional de Saúde (março de 1986), pela primeira vez contando com representaçōes de todos os segmentos sociais interessados na reformulação do Sistema Nacional de Saúde.

O documento final aprovado na VIII Conferência Nacional de Saúde propugna por uma reestruturação no Sistema Nacional de Saúde que caminhe no sentido da criação de um Sistema Único de Saúde.

Esse novo sistema de saúde deverá ser coordenado por um único Ministério, a nível federal, e essa unicidade de comando deverá ser reproduzida a nível estadual e municipal.

Outros princípios para serem estrategicamente incorporados à organização dos serviços de saúde no processo de reestruturação do setor são:

- regionalização de hierarquização dos serviços;

- descentralização na gestão;

- integralidade da atenção à saúde, superando a dicotomia preventivo-curativa;

- universalização da cobertura, com eqüidade, em relação a acesso aos serviços em qualquer nível de atenção;

- respeito à dignidade dos usuários por parte dos servidores e prestadores de serviços de saúde;

- participação, da população organizada, na formulação da política, na gestão, na execução e na avaliação das açōes de saúde.

No que diz respeito a área de RH são as seguintes as proposições:

- remuneração condigna e isonomia salarial entre as mesmas categorias profissionais nos niveis federal, estadual e municipal e estabelecimento urgente e imediato de plano de cargos e salários;

- capacitação e reciclagem permanente;

- admissão através de concurso público;

- estabilidade no emprego;

- composição multiprofissional das equipes, considerando as necessidades da demanda de atendimento de cada região e em consonância com os critérios estabelecidos pelos padrões mínimos de cobertura assistencial;

- compromissos dos servidores com os usuários;

- cumprimento da carga horária contratual e incentivo à dedicação exclusiva;

- formação dos profissionais integrada ao Sistema de Saúde, regionalizados e hierarquizados;

- inclusão no currículo de ensino em saúde do conhecimento de práticas alternativas;

- incorporação dos agentes populares de saúde como pessoal remunerado, sob a coordenação do nível local do Sistema Único de Saúde, para trabalhar em educação para a saúde e cuidados primários. 
Parte dos princípios acima registrados tem sido incorporada às Açōes Integradas de Saúde e esta parece ser no momento a estratégia que facilitará a implementação da Reforma Sanitária pretendida.

Sob esta orientação a área de Recursos Humanos das Instituições de Saúde deverão reorientar suas políticas e estruturar seus бrgãos de desenvolvimento de recursos humanos, para que possam responder ao papel que lhes é inerente na construção do novo Sistema Nacional de Saúde.

Algumas experiências jâ vêm sendo desenvolvidas, na perspectiva da integração, através de Projetos, com ações em alguns estados, que poderão fornecer subsídios para sua institucionalização.

São exemplos típicos dessas experiências integradas o "Projeto Larga Escala", alguns "Cursos de Saúde Pública", a formação de "Comissões Interinstitucionais de Recursos Humanos ligadas às CIS", dentre outras.

$\mathrm{O}$ avanço da discussão com resultados de avaliação desses experimentos poderá contribuir para o aperfeiçoamento das formas de integração entre as instituiçōes, apontando para estruturas, mecanismos e políticas mais próximas das propostas da Reforma Sanitária.

Assim, o exerćcicio de discussão e integração efetiva de temas como: participação no POI-87 com a contribuição especlfica e concreta da área de recursos humanos; gerência de processos de capacitação de forma integrada, a exemplo de Residências, Cursos de Saúde Pública, Programas de Educação Continuada dentre outros; elaboração de concursos conjuntos; busca de mecanismos que viabilizem a curto, médio e longo prazos a isonomia salarial; gestão colegiada da programação anual de $\mathrm{RH}$, poderão se constituir em caminhos que conduzam à consolidação de um novo modelo de formulação $e$ gestão integrada das políticas municipais, estaduais e nacional de Recursos Humanos.

\section{BIBLIOGRAFIA CONSULTADA}

1. BRASIL. Ministério da Saúde. A organização das açöes de desenvolvimento de recursos humanos nas Secretarias de Saúde. Brasflia, 1982. (Textos básicos de saúde).

2. MENDES, E. V. Reformulaçāo do sistema nacional de saúde: visão geral. Brasflia, 1986. (Trabalho apresentado na $8^{\text {a }}$ Conferência Nacional de Saúde. Brastlia, 1986).

3. ROSAS, E. J. A extensão de cobertura dos serviços de saúde no Brasil. Brastlia, 1981. [Dissertação de mestrado, Escola Nacional de Saúde Pública - FIOCRUZ]

4. SAUDE EM DEBATE n $17,1985$.

5. TEIXEIRA, C. F. de S. Educação e saude: contribuição ao estudo da formação dos agentes das práticas de Saúde no Brasil. Salvador, 1982. [Dissertação de mestrado, Faculdade de Medicina UFBa]. 